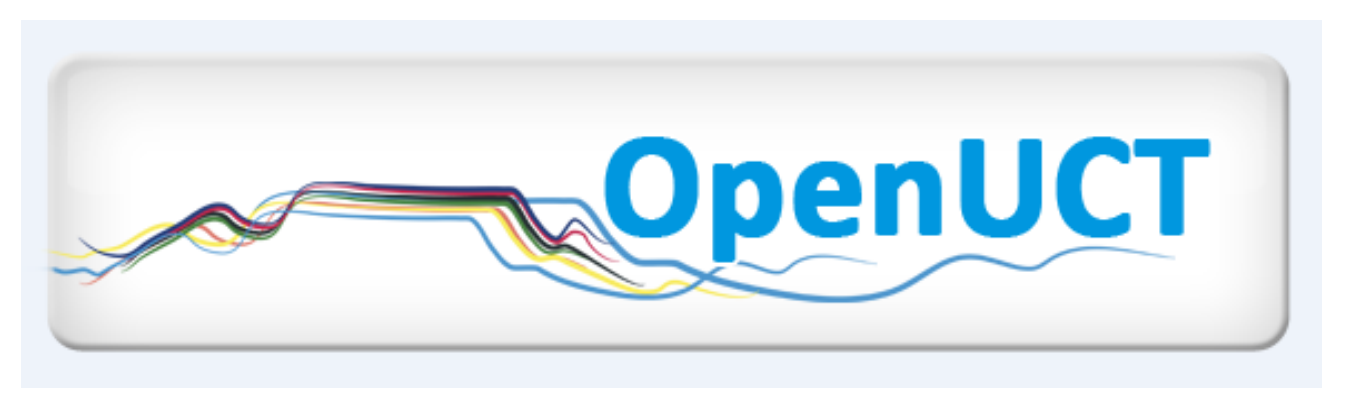

This is the post-print of Smith, L. \& Edwards, L. 2007. A multivariate evaluation of mainstream and academic development courses in first-year microeconomics. South African Journal of Economics. 75(1): 99-117. DOI: 10.1111/j.1813-6982.2007.00102.x.

It is made available according to the terms of agreement between the author and the journal, and in accordance with UCT's open access policy available: http://www.openuct.uct.ac.za/sites/default/files/UCTOpenAccessPolicy.pdf, for the purposes of research, teaching and private study. 


\section{A MULTIVARIATE EVALUATION OF MAINSTREAM AND ACADEMIC DEVELOPMENT COURSES IN FIRST-YEAR MICROECONOMICS}

\section{Abstract}

LEONARD SMITH AND LAWRENCE EDWARDS*

This paper analyses the impact of the University of Cape Town's first-year microeconomics academic development course on performance in examinations. The paper makes two advances to existing empirical literature in this area. Firstly, we compare performance with a control group drawn from the mainstream economic course. Secondly, we evaluate performance in subsequent courses in first-year macroeconomics and second-year microeconomics. The results suggest that the academic development course has a major impact on students' performance in the structured/essay questions, relative to the control group, in first- and second-year microeconomics, and for the multiple-choice questions in first-year macroeconomics. Matriculation results, mathematics, English first language, physical science and gender are also important determinants of performance.

Keywords: academic development, student performance, South Africa, economic education

"There is no place for him [the Bantu] in the European community above the level of certain forms of labour. For that reason it is of no avail for him to receive a training, which has as its aim absorption in the European community, where he cannot be absorbed." (Verwoerd 1954, p. 24)1.

\section{INTRODUCTION}

The pernicious and destructive effects of apartheid in general and Bantu education in particular, on generations of black South Africans are well-known (Davenport, 1978, Walker and Badsha, 1993, Case and Deaton, 1998, Volbrecht, 1999 and Terreblanche, 2002). In their attempts to overcome these constraints the four historically white universities ${ }^{1}$, beginning in the late 1970 s, introduced a wide range of support and development programmes into selected faculties: usually engineering, science and commerce (Moulder, 1991, Walker and Badsha, 1993 and Volbrecht, 1999). These programmes took a variety of forms: extra tutorials, "bridging" courses, and additional courses, usually in English and mathematics, were the norm. Universities were also encouraged to change the manner in which they delivered the curriculum.

\footnotetext{
* Centre for Higher Education Development and School of Economics at the University of Cape Town, respectively.

1 The universities of Cape Town, Natal, Rhodes and the Witwatersrand
} 
Rather than focussing on remedial programmes running alongside mainstream courses they were encouraged to change the content of their degrees and their processes of delivery (Moulder, 1991). Throughout the 1990s universities grappled with the issues surrounding the construction and delivery of academic development programmes (ADP) and courses (Volbrecht, 1999). Yet the efficacy of the courses and programmes, in improving students' academic performance, is largely unknown. There are two main reasons for this unsatisfactory state of affairs. Firstly, relatively little research has been conducted in this area. Secondly, much of the research has been characterised by a variety of methodological deficiencies.

The primary focus of earlier studies in this area was to explain why academically disadvantaged students fail the first-year economics course. Earlier studies were largely qualitative or used simple correlation analysis (Banach, Fuzile and Rampedi, 1992 and Hesketh, Mbali and Mkhize, 1994). Subsequent studies have evaluated the effectiveness of development courses or programmes (Curtis and De Villiers, 1992, De Villiers and Rwigema, 1998 and Edwards, 2000) using more rigorous quantitative techniques. ${ }^{2}$ These studies, however, suffer from potentially severe sample-selection bias as students were not randomly selected into the programmes, but rather chosen on the basis of a number of criteria including their admission rating. A further limitation of most of these studies is that they only evaluate the success of academic development programmes in the first year of study. ${ }^{3}$ The stock of knowledge and learning techniques developed during the academic development programmes are expected to facilitate learning throughout the students' university degree.

In this paper we test the efficacy of a first-year academic development course in microeconomics $(\mathrm{ECO} 110 \mathrm{H})$ offered by the University of Cape Town's School of Economics and the Department of Academic Development using generally accepted econometric techniques. We use the education production function to model the relationship between inputs (explanatory variables) and the output, economic understanding. Our analysis compares performance of the ECO110H cohort with a control group drawn from the mainstream (ECO110S), in both the first-year microeconomics, and subsequent courses in first-year macroeconomics (ECO111S) and second-year microeconomics (ECO203F).

Our study contributes towards the debate and analysis of the efficacy of academic development programmes in three ways. Firstly, an attempt is made to deal with the sample-selection problem by comparing ADP students with a control group. Secondly, we conducted separate estimations for students' performances on the multiple-choice and structured/essay questions in order to gain a better insight into the role of each of the explanatory variables. Thirdly, we examined the importance of the ECO110H course in explaining students' performance in subsequent economics courses. The structure of the paper is as follows. In the following section we describe the development and structure of $\mathrm{ECO} 110 \mathrm{H}$ relative to the university's mainstream courses

\footnotetext{
2 The De Villiers and Rwigema (1998) study also used an ordinary least squares analysis but with a binary dependent variable.

${ }^{3}$ To the authors' knowledge only De Villiers and Rwigema (1998) have addressed this issue.
} 
in first-year microeconomics. ${ }^{4}$ In Section 3 we present the empirical methodology and specification used in this paper. Section 4 considers the data used and discusses the results and Section 5 concludes the paper.

\section{ACADEMIC DEVELOPMENT COURSES IN ECONOMICS}

The University of Cape Town's academic development course in economics has evolved over a number of years in response to a number of perceived constraints on learning experienced by academically disadvantaged students.

Academically disadvantaged students' difficulties generally stem from the fact that they have never been taught to use their cognitive and language skills to analyse complex material in an abstract manner (Moll and Slonimsky, 1989). Insofar as the South African educational system has encouraged learners to rely on rote learning (atomistic or surface processing) it has not encouraged the deep processing of information (De Villiers, 1990, Ramsden, 1992 and Slabbert, 1994). ${ }^{5}$ In addition many South African students who go to university have never been exposed to the ground rules that characterise academic discourse. Students who have English as a second language find it difficult to comprehend the highly abstract language of economics (Paxton, 1998) and many students lack the necessary quantitative and graphical skills necessary for the successful study of economics.

The School of Economics in collaboration with the Department of Academic Development, at the University of Cape Town, developed a two-semester microeconomics course $(\mathrm{ECO} 110 \mathrm{H})$ for academically disadvantaged students to enable them to meet some of these educational challenges. These students do not have sufficient matriculation points to be accepted into the Commerce Faculty, but are reckoned to have the potential, given the right environment, to achieve a Bachelor of Commerce degree. ECO110H forms part of a package of courses that these students are required to take.

This course includes modules on quantitative techniques and graphical analysis and introductory macroeconomics. The theoretical content mirrors that of the shorter single-semester mainstream courses in microeconomics (ECO110F and ECO110S ${ }^{6}$ ) and tests and examinations are set to the same standard. Indeed, from 2001 students doing ECO110S and ECO110H wrote the same final examination.

However, there are some important differences with respect to the structure, content and teaching approach that are expected to enhance academic performance. The ECO110H class runs over two-semesters as opposed to a single semester, 5 lectures are offered per week as opposed to 4 and classes are small (80 to 120 students) relative to the size of mainstream lecture groups (150 to 400 students). Empirical evidence

\footnotetext{
${ }^{4}$ The School of Economics offers two mainstream first-year one-semester microeconomics courses, ECO110F (F refers to first semester) and ECO110S (S refers to second semester). Students who fail ECO110F can repeat the course in the second semester.

${ }^{5}$ Meyer and Shanahan (1999) found that students who rely on rote learning are at greater risk of failing their first year.

${ }^{6}$ ECO110S fills a dual role. It gives students who have failed ECO110F a second opportunity to pass the course, and it makes it possible for students to "pick up" the course, having been unable to do it in the first semester.
} 
suggests that students who are taught in small groups tend to do better in economics examinations than those who are not (Raimondo, Esposito and Gershenberg, 1990 and Lopus, 1990).

Greater emphasis is placed on using the tutorial system as a vehicle to develop students' meta-learning skills. A double-period language and communication tutorial, consisting of about 25 students, is used to improve students' essay writing skills and their referencing and comprehension techniques (Paxton, 1995). Students also take a doubleperiod economics tutorial, consisting of 15 students, where students are required to complete and submit written answers to a set tutorial made up of multiple-choice, paragraph/structured/essay, true/false, fill-in, calculation and case-study questions. The grades received for these assignments contribute towards their final mark.

The economics tutorials offered by the mainstream ECO110F/S pay less attention to the development of students' meta-learning skills. Each week, students attend a singleperiod tutorial during which a various multiple-choice and structured/essay-type questions are discussed. Students are required to submit written work less frequently and their grades for these assignments do not count towards their final marks. Further, no language and communication tutorials are offered.

The assessment of the students during the ADP course also differs from the mainstream course. In addition to the tutorials students are required to complete three essays during the year, and write four tests in addition to the final examination. ${ }^{7}$ The tests include multiple-choice and structured/essay questions in the ratio of about 30 to 70. In contrast, students in the mainstream economics courses are not required to submit essays and their tests consist solely of multiple-choice questions. ${ }^{8}$ These differences in assessment are expected to influence relative performance in a two ways. Firstly, writing enhances students' language and cognitive skills. Secondly, there is strong evidence that multiple-choice examinations discriminate against females (Siegfried and Walstad, 1990 and Harris and Kerby, 1997) and second language speakers (Harris and Kerby, 1997).

ECO110H is designed to enable students, who come from academically and socioeconomically disadvantaged backgrounds, and who have relied on rote learning, to develop their meta-learning, English language, writing and quantitative skills. To the extent that students acquire these skills, their performance in both first-year and future courses in economics and other subjects should be facilitated. In the following section we discuss the empirical methodology used to identify the extent to which performance of academically disadvantaged students is enhanced by the ADP course, ECO110H.

\section{EMPIRICAL METHODOLOGY AND SPECIFICATION}

\section{(a) Specification}

\footnotetext{
7 The final mark was made up as follows:

3 essays at 5\% each (15\%), 3 tests at 5\% each (15\%), 1 test at 10\% (10\%), 20 written economics tutorials $(5 \%)$ and the final examination $(55 \%)$.

${ }^{8}$ The ECO110F/S final mark is made up of the marks gained in two or three multiple-choice tests and the final examination. The tests count $45 \%$ of the final mark. The ECO110F examination paper is made up of multiple-choice and essay questions in the ratio of 50 to 50.
} 
The chief purpose of this paper is to identify the extent to which the academic development course in microeconomics $(\mathrm{ECO} 110 \mathrm{H})$ is successful in improving students' performance in economics relative to a control group drawn from the mainstream (ECO110S). We identify the relationship in two ways. Firstly, we compare performance of ECO110H students with the mainstream ECO110S students using the 2001 final year examination that both sets of students completed at the same sitting. Secondly, we compare performance of these students in the subsequent first-year macroeconomics course (ECO111S) and second-year microeconomics course (ECO203F). To identify the conditional relationship between $\mathrm{ECO} 110 \mathrm{H}$ and performance, we follow most international literature and view economics education as a production process whereby educational performance is a function of a variety of inputs. ${ }^{9}$ This relationship can be represented as:

\section{OUTPUT $=$ F(D110H, STUDENT, SCHOOL, COURSE, OTHER $)$} where:

OUTPUT is a measure of economic performance;

$\mathrm{D} 110 \mathrm{H}$ is a dummy variable that equals 1 for ECO110H students;

STUDENT includes variables measuring student characteristics;

SCHOOL includes variables measuring performance in school-leaving subjects;

COURSE includes variables relating to university course characteristics; and OTHER includes other relevant variables such as place of residence.

Outputs of the production process can include cognitive performance, attitudes and values, and generic skills. In this study we follow Walstad (1990) and use a stock model, whereby we attempt to explain students' stock of economic knowledge or level of economics understanding, as measured by a set of examination results. An alternative approach that we do not follow is to explain economic learning or the change in the stock of knowledge (Becker, 1983a, 1983b and 1983c, and Becker et al., 1991). We however, differentiate between two measures of stock of knowledge, as revealed in examination results for multiple choice questions and essay-type questions. Research suggests that multiple-choice and structured/essay questions measure different dimensions of economics understanding (Walstad and Robson, 1997). This has particular relevance for the investigation of the outcome of an academic development course in economics; the goals of such a course include the students' acquisition of English language, learning, writing and quantitative skills, which are designed to enable them to cope successfully with subsequent, more demanding courses, in economics and other subjects (Edwards, 2000).

The chief purpose of this paper is to assess the effectiveness of an academic development course in economics on students' performance in first- and second-year economics courses. We identify this relationship using a dummy variable, D110H, that equals 1 for ECO110H students. A positive sign for the coefficient of D110H suggests that the academic development programme exerts a positive influence on students' economics performance relative to the other students. To obtain the conditional impact

\footnotetext{
${ }^{9}$ However this is not always the case. For example, Shanahan et al. (1997), and Meyer and Shanahan (1999), used cluster analysis to assess the determinants of students' performance in university economics.
} 
of ECO110H on economic performance, we include a number of other variables that may explain economic performance. These include variables for performance in schoolleaving subjects, course characteristics and student characteristics and are selected on the basis of international literature. These are now briefly discussed.

Proxies for academic ability are important in explaining students' academic performance at university (Anderson, Benjamin and Fuss, 1994, Robb and Robb, 1999 and Van Walbeek, 2004). This relationship also holds for academic development students (De Villiers and Rwigema, 1998, Curtis and De Villiers, 1992 and Edwards, 2000). We follow Edwards (2000) and Van Walbeek (2004) and use a modified version of the matriculation points score used by the University of Cape Town as a measure of academic ability. ${ }^{10}$ The unadjusted matriculation score includes double points for mathematics and English. Because we include independent variables for these subjects, we deduct the points allocated to these subjects. Two points are also deducted in respect of physical science taken at the higher grade level, as this subject is also treated as an independent variable. The coefficient of the matriculation score is expected to be positive for both the multiple-choice and structured/essay type questions. To allow for non-linearity the square of this variable is also included.

Some school-leaving subjects are included to capture students' ability, knowledge and skills that facilitate economics understanding. High-school English has been included in many studies, but the results are mixed (Myatt and Waddell, 1990, Anderson, Benjamin and Fuss, 1994 and Van Walbeek, 2004). Competence in mathematics is generally found to be strongly associated with economics performance (Raimondo, Esposito and Gershenberg, 1990, Myatt and Waddell, 1990, Hesketh, Mbali and Mkhize, 1994 and Van Walbeek, 2004). Completion of physical science (physics and chemistry) has been shown to positively correlated with economics understanding in the South African literature (Edwards, 2000 and Van Walbeek, 2004), but has not been analysed in the international literature.

The results of studies on the effect of high-school or prior economics courses on economic understanding at the tertiary level are mixed. Statistically positive effects were found by Lumsden and Scott (1987), Myatt and Waddell (1990), Brasfield, Harrison and McCoy (1993) and Tay (1994). A number of studies have shown that prior economics courses have little or no effect on economics performance at the tertiary level (Siegfried and Fels 1979, Siegfried and Walstad 1990 and Becker, Greene and Rosen, 1990). Reid (1983) and Robb and Robb (1999) found statistically significant negative effects. In South African studies, Edwards (2000) reports a statistically significant positive effect for this variable.. There are two possible explanations for these mixed results. Firstly, there may be no clear match between the content of the high-school economics course and the content of the first year university course (Reid, 1983 and Lopus, 1997). Secondly, academically strong students tend not to take economics at school (Peterson, 1992 and Anderson, Benjamin and Fuss, 1994). In South Africa academically weaker students tend to opt for business economics and economics as alternatives to the sciences and mathematics on the higher grade. A negative relationship for this variable

10 The University of Cape Town allocates points to matriculation subjects as follows: Higher Grade: $A=8, B=7, C=6, D=5, E=4, F=3$. Standard Grade: Two points less for each grade. The Commerce Faculty doubles the points for mathematics and English. 
may therefore reflect selection bias rather than the negative impact of school economics on economics understanding.

To capture the effect of these school-leaving subjects we include dummy variables for various grade combinations $(A+B, C, D, E+F)$ obtained for English first language (HG), mathematics (HG) and physical science (HG). We expect progressively higher positive coefficients as the grade improves. This approach is only followed in analysing the first year micro-economic results. Due to data limitations, we only include dummy variables for each of English first language (HG), mathematics (HG) and physical science $(\mathrm{HG})$ when analysing performance in the subsequent courses (ECO111S and ECO203F). We include a dummy variable for completion of high-school economics in all cases.

There are strong grounds for expecting English (home language) to have a positive impact on economics performance at universities where English is the medium of instruction (Banach, Fuzile and Rampedi, 1992, Harris and Kerby, 1997, Meyer and Shanahan, 1999 and Edwards, 2000). We therefore include a dummy variable that equals 1 if the student's home language is English. Several studies report that females perform relatively well in essay questions, but relatively worse in multiple-choice questions (Siegfried and Walstad, 1990, Harris and Kerby, 1997, Edwards, 2000, and Van Walbeek, 2004). We therefore include a dummy variable that equals 1 if the student is male.

Students' population group classification is not included as a variable in this study. It is our view that it is more productive to focus on the underlying variables if one wishes to gain a useful insight into the determinants of economics performance. That said all estimations were run including population-group dummies. In only one estimation was the coefficient for the dummy variable statistically significant at the $5 \%$ level. A dummy is included for students who live in one of the many university residences. Dummies are not included for the current and former education departments. In a similar study done on the 2000 cohort (Smith, 2004), the coefficients for schools administered by the Department of Education and Training ${ }^{11}$ and the former Houses of Delegates and Representatives were found to be statistically insignificant.

\section{(b) Estimation issues and limitations}

While we have included a range of explanatory variables in order to identify the conditional impact of ECO110H on performance, important variables such as students' effort, attitude and motivation have been omitted as it is difficult to find suitable proxies. The omission of these variables may result in biased estimates of the coefficients. In particular, if these omitted variables are correlated with ECO110H, we may erroneously attribute their effect on economic performance to our ECO110H dummy variable.

A further constraint to our analysis is that students doing the academic development course are exposed to more than double the teaching time than students who successfully complete the microeconomics course within a single semester. However, our study compares performance with students who have registered for the secondsemester microeconomics course (ECO110S). Most of the students registered for

11 The Department of Education and Training, formerly known as the Department of Bantu Education, had responsibility for the education of black children from 1954 to 1994. 
ECO110S are repeating the first-year microeconomics course, having failed the firstsemester course, ECO110F. Only a relatively small number $(12 \%)$ are doing economics for the first time. The allocation of teaching resources to these students is thus roughly comparable.

A more important consideration relates to possible sample-selection problems. The ECO110S cohort can only act as a control group if it is drawn from the same population as the ECO $110 \mathrm{H}$ cohort. ${ }^{12}$ We identify two sample-selection issues and take the following steps to deal with them.

Firstly, not all students complete the course and the exclusion of these in the estimation may lead to sample-selection bias (Douglas and Sulock, 1995). This problem applies to both the ECO110H and ECO110S cohorts: $10.8 \%$ of the ECO110H cohort and $11.2 \%$ of the ECO110S cohort did not complete the course. Given that the percentages for the two courses are very similar it is assumed that any selection bias is evenly applied across both cohorts.

The second sample-selection issue is whether students doing ECO110H and ECO110S are drawn from the same population measured across a broad range of characteristics. If not, then the difference in the performance of the ECO110H cohort might be due to their differing set of characteristics rather than the effectiveness of the teaching embodied in the ECO110H course. To test for the extent of the similarity between the two cohorts, differences of means and proportions tests were conducted for each of the continuous and discrete variables for the full samples. Table 1 compares variables used in the analysis of first-year microeconomics, while Table 2 compares the variables used in the analysis of the subsequent macroeconomics (ECO111S) and microeconomics (ECO203F) courses. The ECO110H and ECO110S cohorts used for this study date from 2001. These cohorts wrote the first-year microeconomics examination in November 2001, the first-year macroeconomics examination in November 2002, and the second-year microeconomics examination in June 2002. It is clear that the two cohorts differ markedly from one another; in almost all cases we reject the null hypothesis of equal means. For example, the mean matriculation points score for ECO110S cohort is greater than the mean score for the ECO110H cohort. The proportion of students taking economics and business economics is greater for the $\mathrm{ECO} 110 \mathrm{H}$ cohort, and black students make up a larger proportion of the $\mathrm{ECO} 110 \mathrm{H}$ cohort. More importantly, the ECO110S cohort shows a strong bias towards mathematics (HG), English first language (HG) and physical science (HG).

To reduce the extent of the difference between the two cohorts, students who obtained more than 36 , or less than 20 , matriculation points were excluded from the full samples in order to maximise the overlap of the two cohorts. Also, those students on the Commerce Academic Programme (44 in all) were excluded from the full samples described above. These students are selected on the basis of different criteria compared to other students who are doing the ECO110H course. For example, prospective students are interviewed prior to being made an offer. Also, CADP students have the on-going support of a full-time programme convener. ${ }^{13}$ The differences between the

\footnotetext{
12 There is an extensive literature on sample-selection problems - this literature includes Park and Kerr (1990) and Raimondo, Esposito and Gershenberg (1990).

${ }^{13}$ Further, anecdotal evidence suggests that they may have higher levels of motivation and a more positive attitude towards economics.
} 
ECO110H and ECO110S cohorts are reduced for the truncated samples (Table 1 and Table 2) but they remain statistically significant at the $5 \%$ level for most of the variables. These findings suggest the possibility of sample-selection bias even after truncating the sample.

Table 1. Control variables for first-year microeconomics

\begin{tabular}{|c|c|c|c|c|c|c|}
\hline & $\mathrm{Fu}$ & ll sample & & Trunc & ated sam & ple \\
\hline & $\begin{array}{l}\text { ECO } \\
110 \mathrm{H}\end{array}$ & $\begin{array}{l}\text { ECO } \\
110 S\end{array}$ & Diff & $\begin{array}{l}\text { ECO } \\
110 \mathrm{H}\end{array}$ & $\begin{array}{l}\text { ECO } \\
110 S\end{array}$ & Diff \\
\hline Personal characteristics & $\%$ share & $\%$ share & & $\%$ share & $\%$ share & \\
\hline English home language (Enghome) & $46.4 \%$ & $63.9 \%$ & 8.65 & $63.7 \%$ & $62.9 \%$ & 1.36 \\
\hline Indian & $6.2 \%$ & $8.3 \%$ & 5.83 & $8.8 \%$ & $7.6 \%$ & 2.96 \\
\hline White & $17.0 \%$ & $44.8 \%$ & 11.60 & $35.2 \%$ & $42.4 \%$ & 4.04 \\
\hline Coloured & $21.6 \%$ & $16.5 \%$ & 5.91 & $19.8 \%$ & $15.2 \%$ & 4.19 \\
\hline Black & $55.2 \%$ & $30.4 \%$ & 10.35 & $36.3 \%$ & $34.8 \%$ & 1.88 \\
\hline Male (Male) & $58.8 \%$ & $50.0 \%$ & 6.11 & $62.6 \%$ & $59.8 \%$ & 2.52 \\
\hline Residence (Residence) & $57.2 \%$ & $49.1 \%$ & 5.85 & $42.9 \%$ & $45.5 \%$ & 2.38 \\
\hline $\begin{array}{l}\text { ECO110S students first registration } \\
\text { for ECO110 (First time) }\end{array}$ & $0 \%$ & $12.0 \%$ & & $0 \%$ & $18.2 \%$ & \\
\hline Matriculation subjects & $\%$ share & $\%$ share & & $\%$ share & $\%$ share & \\
\hline $\begin{array}{l}\text { English first language (HG) } \\
\text { (Eng FL HG) }\end{array}$ & $66.5 \%$ & $82.2 \%$ & 9.39 & $76.9 \%$ & $81.8 \%$ & 4.06 \\
\hline Mathematics (HG) (Math HG) & $41.8 \%$ & $68.7 \%$ & 10.72 & $27.5 \%$ & $56.8 \%$ & 7.99 \\
\hline Physical science (HG) (PS HG) & $36.6 \%$ & $60.4 \%$ & 10.01 & $33.0 \%$ & $57.6 \%$ & 7.28 \\
\hline Business Economics (Busecon) & $28.4 \%$ & $17.4 \%$ & 8.21 & $24.2 \%$ & $18.2 \%$ & 4.41 \\
\hline Economics (Economics) & $24.2 \%$ & $13.9 \%$ & 8.39 & $24.2 \%$ & $14.4 \%$ & 5.98 \\
\hline Matriculation points & Mean & Mean & & Mean & Mean & \\
\hline $\begin{array}{l}\text { Mean matriculation points score } \\
\text { (Matpt) }\end{array}$ & 31.7 & 35.8 & 11.20 & 30.2 & 32.9 & 8.58 \\
\hline $\begin{array}{l}\text { Mean adjusted matriculation points } \\
\text { score (Adjmatpt) }\end{array}$ & 21.2 & 23.0 & 5.70 & 20.4 & 21.0 & 1.74 \\
\hline Observations & 194 & 230 & & 91 & 132 & \\
\hline
\end{tabular}

Note: The column titled "Difference" provides the $t$ and $z$-statistics for the test of equality of means and proportions between ECO110H and ECO110S students.

However, the extent of this problem may not be that significant. Firstly, there may be substantial random error associated with the main variable used to select students into ECO110H, namely matriculation grades. The matriculation examinations differ across province and the papers are graded by teams of examiners across provinces. Secondly, the adjusted matriculation scores for $\mathrm{ECO} 110 \mathrm{H}$ and ECO110S students in the full and truncated sample are not significantly (at 5\% level) different from each other.

Nonetheless, due consideration must still be given to potential sample-selection problems when interpreting the results. 
Table 2. Control variables for subsequent courses in macroeconomics (ECO111S) and microeconomics (ECO203F)

\begin{tabular}{lllllll} 
& \multicolumn{2}{l}{ Full sample } & & \multicolumn{3}{c}{ Truncated sample } \\
ECO & ECO & ECO & Diff & ECO & ECO & Diff \\
$110 F$ & $110 \mathrm{H}$ & $110 \mathrm{~S}$ & & $110 \mathrm{H}$ & $110 \mathrm{~S}$ &
\end{tabular}

\begin{tabular}{|c|c|c|c|c|c|c|c|}
\hline \multicolumn{8}{|l|}{ ECO111S } \\
\hline & & $\%$ share & $\%$ share & & $\%$ share & $\%$ share & \\
\hline Male $(\%$ of total $)$ & $58.6 \%$ & $57.6 \%$ & $56.7 \%$ & 0.70 & $65.4 \%$ & $63.4 \%$ & 0.83 \\
\hline \multicolumn{8}{|l|}{ School subjects } \\
\hline $\begin{array}{l}\text { English first language (HG) } \\
\text { (Eng FL HG) }(\% \text { of total) }\end{array}$ & $95.0 \%$ & $68.8 \%$ & $86.7 \%$ & 3.14 & $82.7 \%$ & $85.4 \%$ & 1.00 \\
\hline $\begin{array}{l}\text { Mathematics (HG) (Math HG) } \\
(\% \text { of total) }\end{array}$ & $89.8 \%$ & $48.8 \%$ & $63.3 \%$ & 2.79 & $40.4 \%$ & $63.4 \%$ & 2.83 \\
\hline $\begin{array}{l}\text { Physical Science (HG) (PS HG) } \\
(\% \text { of total) }\end{array}$ & $77.3 \%$ & $41.6 \%$ & $53.3 \%$ & 2.50 & $42.3 \%$ & $53.7 \%$ & 1.98 \\
\hline Matriculation points & & Mean & Mean & & Mean & Mean & \\
\hline Matriculation points (Matpt) & 41.2 & 32.3 & 34.7 & 4.59 & 30.8 & 32.6 & 3.93 \\
\hline $\begin{array}{l}\text { Adjusted matriculation points } \\
\text { (Adjmatpt) }\end{array}$ & 26.4 & 21.8 & 22.5 & 1.45 & 21.1 & 21.0 & 0.01 \\
\hline Observations & 920 & 125 & 60 & & 52 & 41 & \\
\hline \multicolumn{8}{|l|}{ ECO203F } \\
\hline & & $\%$ share & $\%$ share & & $\%$ share & $\%$ share & \\
\hline Male $(\%$ of total) & $57.4 \%$ & $53.1 \%$ & $41.5 \%$ & 2.26 & $57.1 \%$ & $45.8 \%$ & 1.57 \\
\hline \multicolumn{8}{|l|}{ School subjects } \\
\hline $\begin{array}{l}\text { English first language (HG) } \\
\text { (Eng FL HG) (\% of total) }\end{array}$ & $91.6 \%$ & $90.6 \%$ & $77.4 \%$ & 2.52 & $82.1 \%$ & $79.2 \%$ & 0.83 \\
\hline $\begin{array}{l}\text { Mathematics (HG) (Math HG) } \\
(\% \text { of total) }\end{array}$ & $83.8 \%$ & $67.2 \%$ & $67.9 \%$ & 0.56 & $35.7 \%$ & $54.2 \%$ & 2.01 \\
\hline $\begin{array}{l}\text { Physical Science (HG) (PS HG) } \\
(\% \text { of total) }\end{array}$ & $73.5 \%$ & $56.3 \%$ & $52.8 \%$ & 1.24 & $35.7 \%$ & $37.5 \%$ & 0.63 \\
\hline Matriculation points & & Mean & Mean & & Mean & Mean & \\
\hline Matriculation points (Matpt) & 39.4 & 33.1 & 36.6 & 4.86 & 30.8 & 32.9 & 3.15 \\
\hline $\begin{array}{l}\text { Adjusted matriculation points } \\
\text { (Adjmatpt) }\end{array}$ & 25.2 & 21.8 & 23.8 & 3.43 & 21.4 & 21.7 & 0.35 \\
\hline Observations & 925 & 64 & 53 & & 28 & 24 & \\
\hline
\end{tabular}

Note: The column titled "Diff' provides the $t$ and z-statistics for the test of equality of means and proportions between ECO110H and ECO110S students.

\section{DATA AND RESULTS}

(a) Analysis of data

In this section we briefly compare the examination grades of the $\mathrm{ECO} 110 \mathrm{H}$ students with the ECO110F/S students. The examination results for first-year microeconomics are presented in Table 3. These results show that the ECO110H students outperformed the ECO110S students by 8.4 percentage points in the structured/essay questions for the full sample and by 6.4 percentage points for the truncated sample (statistically significant at the $1 \%$ level). However, the ECO110S cohort had the greater success in the multiple-choice component of the final examination. Overall, the ECO110H cohort appears to outperform the ECO110S cohort despite the fact that they exhibit a lower level of academic ability as measured by their performance in the matriculation examination (Table 1). 
Table 3. Examination results and t-statistics for the first-year microeconomics examination

\begin{tabular}{c} 
Full sample \\
\multicolumn{3}{c}{ Truncated sample } \\
$110 \mathrm{H} \quad 110 \mathrm{~S}$ t-stat $110 \mathrm{H} \quad 110 \mathrm{~S}$ t-stat
\end{tabular}

Examination results

$\begin{array}{llllllll}\text { Structured/essay questions (SQ) \% } & 46.2 & 37.8 & 6.26^{* *} & 41.9 & 35.5 & 3.39^{* *}\end{array}$

$\begin{array}{llllllll}\text { Multiple-choice questions (MCQ) \% } & 57.3 & 59.8 & 1.56 & 54.3 & 58.0 & 1.69 *\end{array}$

$\begin{array}{lllllll}\text { Examination (exam) \% } & 49.8 & 45.1 & 3.79 * * & 46.0 & 43.0 & 1.65^{*}\end{array}$

Observations $\quad 194 \quad 230 \quad \frac{13}{* *}$ and $*$ represent statistical significance at $1 \%$ and $5 \%$, respectively.

Table 4 compares the average examination grades of the successful ECO110H and ECO110S students in the subsequent first-year macroeconomics (ECO111S) and second-year microeconomics (ECO203F) courses. The grades of those students who successfully passed the first-semester microeconomic course, ECO110F, are also presented. ${ }^{14}$ The ECO110H cohort outperforms the ECO110S cohort in the multiplechoice and structured/essay questions in both examinations and in both the full and truncated samples. The differences, however, are only statistically significant for the multiple-choice question results in the truncated sample for the first-year macroeconomics exam (ECO111S) and the structured/essay questions (SQ) in both samples for the second-year microeconomics (ECO203F) examination. However, in both courses the results achieved by the ECO110H and ECO110S cohorts compare unfavourably with the achievements of their peers from the mainstream microeconomics course, ECO110F. For example, the average mark achieved by the ECO110F cohort for the structured/essay questions in the ECO203F examination exceeds that achieved by students from the ECO110H cohort (full sample) by 6.2 percentage points.

Table 4. Examination results and t-statistics for subsequent courses in macroeconomics (ECO111S) and microeconomics (ECO203F)

$\begin{array}{lccc} & \text { Obs } & \text { MCQs } & \text { SQs } \\ & & & \\ \text { ECO111S } & & & \\ \text { Full samples } & 125 & 57.7 & 51.8 \\ \text { ECO110H } & 60 & 55.1 & 48.8 \\ \text { ECO110S } & & 1.32 & 1.49 \\ \text { t-statistic ECO110H and ECO110S } & & \\ \text { Truncated samples } & 52 & 58.5 & 50.8 \\ \text { ECO110H } & 41 & 53.0 & 47.8 \\ \text { ECO110S } & & 2.10^{* *} & 1.10 \\ \text { t-statistic ECO110H and ECO110S } & 920 & 68.4 & 57.4 \\ \text { ECO110F } & & & \\ & & & \\ \text { ECO203F } & & & \\ \text { Full samples } & 64 & 41.6 & 44.6 \\ \text { ECO110H } & 53 & 40.5 & 39.2 \\ \text { ECO110S } & & 0.38 & 2.48^{* *} \\ \text { t-statistic ECO110H and ECO110S } & & & \\ \text { Truncated samples } & 28 & 40.7 & 45.5 \\ \text { ECO110H } & 24 & 37.0 & 34.3 \\ \text { ECO110S } & & 0.85 & 3.64^{* *} \\ \text { t-statistic ECO110H and ECO110S } & 925 & 53.4 & 50.8 \\ \text { ECO110F } & & \end{array}$

14 Both courses were taken in 2002. For ECO111S, the ECO110H and ECO110S cohorts are compared to the cohort of students who did ECO110F in 2002. For ECO203F the comparison is with the cohort who did ECO110F in 2001. 
Note: ${ }^{* *}$ and $*$ represent statistical significance at $1 \%$ and $5 \%$, respectively.

In summary, relative to the ECO110S cohort, ECO110H students tend to achieve better examination results in both the first-year microeconomics course, and subsequent first-year macroeconomics and second-year microeconomics courses. In particular, ECO110H students appear to enjoy a greater advantage in the structured/essay, as opposed to the multiple-choice, questions.

\section{(b) First-year microeconomics results}

To evaluate the impact of the academic development course $(\mathrm{ECO} 110 \mathrm{H})$ on performance in first-year microeconomics, we estimate the production function represented by equation (1) using ordinary least squares. Two specifications are estimated. Firstly, we estimate equation (1) using the multiple-choice question results in the final examination as the dependent variable and the variables in Table 1 as explanatory variables. Secondly, we estimate the same relationship using the examination results for the structured/essay questions. We apply these regressions to the full data sample and to the truncated data sample. Table 5 presents the results of the estimations. Further, we also estimate an extended specification that includes the interaction between $\mathrm{D} 110 \mathrm{H}$ and a number of variables, and the square of the adjusted matriculation score. These estimations yielded limited additional insight. Therefore, the relevant table is included in Appendix A.

Looking first at the multiple-choice question results, we find no evidence that ECO110H students perform better than ECO110S students conditional on the other explanatory variables. In neither the full nor truncated sample is the dummy variable D110H statistically significant at or below the 10\% level. The regressions, including interaction terms (see Appendix A), also yield no significant results for ECO110H. The performance of $\mathrm{ECO} 110 \mathrm{H}$ students in multiple-choice questions seems to be equivalent to other students given the effect of other variables included in the regressions.

However, we find significant (at 1\% level) positive coefficients for $\mathrm{D} 110 \mathrm{H}$ in the structured/essay question regressions. The coefficients imply that ECO110H students achieve an average of 15.6 to 15.9 percentage points more than the ECO110S cohort, conditional on all the other variables. This result is consistent with the emphasis placed on English language and writing skills in the academic development course. Further interrogation of this result in the regression including interaction effects suggests that the improved performance is concentrated amongst ECO110H students with relatively high matriculation scores. The coefficient on the interaction term between $\mathrm{D} 110 \mathrm{H}$ and matriculation points score indicates that a 1 unit increase in the adjusted matriculation points of ECO110H students raises their performance in first-year microeconomics examination by 1.2 to 2.7 percentage points.

Looking at the other variables, we tend to find results consistent with other studies in this field (Lumsden and Scott, 1987, Walstad and Soper, 1989, Siegfried and Walstad, 1990 and Harris and Kerby, 1997). A background in higher grade mathematics improves performance in multiple-choice tests. The average grade of students who achieved an A, B or C in mathematics (HG) was 3.3 to 8.2 percentage points higher than standard grade students, and 5.0 to 7.3 percentage points higher for students who achieved an E or F. However, school-leaving mathematics is not significant in 
explaining performance in the structured/essay questions, except for students who achieved a grade of $\mathrm{E}$ or $\mathrm{F}$ in mathematics high-grade. ${ }^{15}$

Table 5. Results of the multiple-choice and structured/essay question estimations for the first-year microeconomics examination

\begin{tabular}{|c|c|c|c|c|}
\hline \multirow[b]{2}{*}{ Variable } & \multicolumn{2}{|c|}{$\begin{array}{l}\text { Multiple-choice question (MCQ) } \\
\text { sample } \\
\text { Simple estimations }\end{array}$} & \multicolumn{2}{|c|}{$\begin{array}{c}\text { Structured/essay question (SQ) } \\
\text { sample } \\
\text { Simple estimations }\end{array}$} \\
\hline & Full (1) & Truncated (2) & Full (3) & Truncated (4) \\
\hline $\mathrm{C}$ & $23.21 * * *$ & $16.58^{* *}$ & $20.05^{* *}$ & $22.09^{*}$ \\
\hline $\mathrm{D} 110 \mathrm{H}$ & 1.47 & 2.06 & $15.85^{* * *}$ & $15.63^{* * *}$ \\
\hline Adjmatpt & $0.41 * *$ & $0.77 * *$ & $0.86^{* * *}$ & 0.86 \\
\hline D Busecon & $-3.16^{* *}$ & -2.43 & -3.38 & -1.16 \\
\hline D Economics & -1.05 & -2.65 & -2.58 & $-7.79 * *$ \\
\hline D Eng FL HG AB & $3.94 * *$ & 2.74 & $7.15^{* *}$ & 6.70 \\
\hline D Eng FL HG C & 0.08 & -2.14 & 0.87 & 0.11 \\
\hline D Eng FL HG D & 1.19 & & 0.37 & \\
\hline D Eng FL HG E & 4.8 & & 10.51 & \\
\hline D Math HG AB & $4.86^{* * *}$ & & 1.48 & \\
\hline D Math HG ABC 1 & & $8.22 * * *$ & & 3.04 \\
\hline D Math HG C & $3.3^{* *}$ & & 0.40 & \\
\hline D Math HG D & 1.69 & 2.14 & 3.01 & -0.86 \\
\hline D Math HG EF & $5.04^{* * *}$ & $7.30^{* * *}$ & $6.74 * *$ & $7.32 * *$ \\
\hline D PS HG AB & 1.57 & & 4.40 & \\
\hline D PS HG $\mathrm{ABC}^{1}$ & & 0.39 & & 1.80 \\
\hline D PS HG C & -0.49 & & 0.52 & \\
\hline D PS HG D & 0.78 & 1.03 & 2.17 & 4.87 \\
\hline D Commerce ${ }^{2}$ & $2.3^{* *}$ & $3.25^{*}$ & $5.82 * * *$ & $7.05^{* *}$ \\
\hline D English home & $-2.77 * *$ & $-3.57^{*}$ & $-5.71 * *$ & $-10.32^{* * *}$ \\
\hline D First time & -0.08 & -1.76 & $5.22 * *$ & 4.28 \\
\hline D Male & $2.82^{* * *}$ & $3.71 * * *$ & 0.93 & $5.02 * *$ \\
\hline D Residence & $-2.82^{* *}$ & $-4.72^{* * *}$ & -2.12 & $-7.94^{* * *}$ \\
\hline $\mathrm{R}^{2}$ & 0.161 & 0.235 & 0.223 & 0.207 \\
\hline adj. $R^{2}$ & 0.119 & 0.167 & 0.184 & 0.136 \\
\hline F-stat. & $3.87^{* * *}$ & $3.46^{* * *}$ & $5.78^{* * *}$ & $2.94^{* * *}$ \\
\hline Observations & 424 & 223 & 424 & 223 \\
\hline
\end{tabular}

Notes:

${ }^{1}$ Too few observations for grades A and B only.

${ }^{2} \mathrm{ECO} 110 \mathrm{H}$ commerce students excluded from the truncated sample.

$* * *, * *$ and $*$ represent statistical significance at $1 \%, 5 \%$ and $10 \%$, respectively. White

heteroskedasticity consistent standard errors and covariance test is used for all estimations.

These results indicate that a background in mathematics contributes positively towards achievement in first-year microeconomics. Some $60 \%$ of the ECO110H cohort, and $30 \%$ of the ECO110S cohort, enter the ECO110S and ECO110H courses with only standard grade mathematics. Improving the content of and support for the mathematics component of microeconomics may yield important returns in terms of improved student performance.

English first language (HG) grades $\mathrm{A}$ and $\mathrm{B}$ (Eng FL HG $A B$ ) are positively related to performance in both the multiple-choice and structured/essay questions for the full sample, but are statistically insignificant for the truncated sample. The advantage ranges from 3.9 to 7.2 percentage points (Columns 1 and 3) compared to students who

1554 of the 239 , or $22.6 \%$, of the students achieved an E or F for mathematics HG, This finding may warrant further investigation. 
achieve less than a B grade, or who have taken English as a second language. Students with relatively poor language skills in general appear to be at some disadvantage in answering both types of questions. The coefficients for business economics (Busecon) and economics (Economics) range from -3.2 to -7.8, but are not significant in all regressions. The sign, however, is negative in all cases, indicating that high-school courses in Economics do not contribute towards improved performance in first-year university level microeconomics. These results contrast with those of Edwards (2000) who finds a positive coefficient.

The coefficient of the adjusted matriculation points score (Adjmatpt) is positive and statistically significant in all regressions except for the structured/essay question regression using the truncated data. A 1.0 unit increase in the adjusted matriculation points score increases performance by 0.4 to 0.8 percentage points in the multiplechoice questions (Columns 1 and 2) and approximately 0.9 percentage points in the structured/essay questions (Column 3). Similar results are reported by Edwards (2000) and Van Walbeek (2004).

Our results regarding the performance of male students relative to female students are largely consistent with international and domestic studies. Male students achieved an average of 2.8 to 3.7 percentage points more than female students for the multiplechoice questions. However, the coefficient is insignificant in the case of the structured/essay questions when using the full sample, although it is positive and significant (5.0) for the truncated sample. Therefore, we find more consistent evidence of a gender bias associated with the multiple-choice questions compared to the structured/essay style questions. Similar results have also been found by Lumsden and Scott (1987), Walstad and Soper (1989), Siegfried and Walstad (1990) and Harris and Kerby (1997).

Looking at the other variables, we find that English home language (Enghome) has a negative coefficient ranging from -2.8 to -10.3 across all the estimations, which is contrary to our priors and Edwards' (2000) results. There are two possible explanations for this result. Firstly, students may declare English to be their home language when it is not, and secondly, the English used at home may take the form of a patois that does not facilitate learning in the university environment.Finally, we find that students perform relatively poorly if they resided in university residences (Residence) ${ }^{16}$ and/or are not from the Commerce Faculty.

Overall, the results provide some evidence that ECO110H contributes positively towards performance in microeconomics, particularly in the structured/essay questions. This suggests that the interventions incorporated in the ECO110H course, to improve students' learning, English language, writing and quantitative skills were partly successful in enabling students to overcome some of their educational disadvantages. However, the gains are concentrated among those students with superior matriculation results, indicating that more effort may be required to deal with learning disadvantages amongst the weaker students. Also, ECO110H is not statistically significant in explaining students' performance in the multiple-choice questions. This may reflect the need for further development of the mathematics component of the ECO110H course, as mathematical ability is shown to enhance performance in multiple-choice exams. This policy, however, is not specific to ECO110H and can be extended to ECO110S

${ }^{16}$ See De Villiers (2004) for a detailed discussion and analysis of this topic. 


\section{(c) Subsequent courses in economics}

One of the main aims of first-year academic programmes is to teach students skills that enable them to succeed in courses taken in subsequent years. A useful test of this outcome is an evaluation of the performance of ECO110H compared to other students in subsequent economics courses. In this section the performance of successful ECO110H and ECO110S students is compared in first-year macroeconomics (ECO111S) and second-year microeconomics (ECO203F). In all cases we compare performance relative to the successful first-semester ECO110F students.

Two sets of simple (linear) equations are estimated (full and truncated samples), with the marks for the multiple-choice and structured/essay type questions acting as dependent variables. Dummies are included for each of the ECO110H (D110H) and ECO110S (D110S) variables. The performance of the two cohorts is then estimated relative to the omitted variable, the performance of the ECO110F cohort.

Table 6 shows that the ECO110S students perform significantly worse than the academic development $(\mathrm{ECO} 110 \mathrm{H})$ students in both the multiple-choice and structured/essay questions in most of the estimations. In contrast the performance of the ECO110H cohort does not appear to be statistically different from that of the ECO110F students.

Comparing the academic development students (ECO110H) with the ECO110S cohort we note that the former perform significantly better than the latter in the multiplechoice questions in the first-year macroeconomics examination (ECO111S). This is not the case in the second-year microeconomics course (ECO203F) where the difference between the two coefficients for the ECO110H and ECO110S cohorts is statistically insignificant. This suggests that the advantage enjoyed by the ECO110H cohort, relative to the ECO110S cohort, in multiple-choice tests dissipates over time.

Table 6. Results of the multiple-choice and structured/essay question estimations for the ECO111S and ECO203F examinations

\begin{tabular}{|c|c|c|c|c|c|c|c|c|}
\hline \multirow{4}{*}{ Variable } & \multicolumn{4}{|c|}{$\begin{array}{c}\text { Multiple-choice question (MCQ) sample } \\
\text { Simple estimations }\end{array}$} & \multicolumn{4}{|c|}{$\begin{array}{c}\text { Structured/essay question (SQ) sample } \\
\text { Simple estimations }\end{array}$} \\
\hline & \multicolumn{2}{|c|}{ ECO111S } & \multicolumn{2}{|c|}{ ECO203F } & \multicolumn{2}{|c|}{ ECO111S } & \multicolumn{2}{|c|}{ ECO203F } \\
\hline & Full & Trunc & Full & Trunc & Full & Trunc & Full & Trunc \\
\hline & 1 & 2 & 3 & 4 & 5 & 6 & 7 & 8 \\
\hline $\mathrm{C}$ & $18.19^{* * *}$ & $15.71^{* * *}$ & -4.06 & $-6.87 *$ & $25.45^{* * *}$ & $25.35^{* * *}$ & $20.69 * * *$ & $19.23^{* * *}$ \\
\hline D110H & -1.13 & 1.25 & -3.33 & 0.59 & 0.28 & 0.22 & -1.64 & 1.82 \\
\hline D110S & $-5.56^{* * *}$ & $-4.98^{* *}$ & $-7.68^{* * *}$ & -4.59 & $-3.46^{*}$ & -2.95 & $-11.11 * * *$ & $-12.54 * * *$ \\
\hline Adjmatpt & $1.62^{* * *}$ & $1.68^{* * *}$ & $1.84^{* * *}$ & $1.90^{* * *}$ & $0.91 * * *$ & $0.92^{* * *}$ & $1.45^{* * *}$ & $1.46^{* * *}$ \\
\hline D Eng FL HG & 1.07 & 1.20 & 0.06 & 0.43 & 0.00 & -0.09 & 1.62 & 2.15 \\
\hline D Math HG & 0.32 & 0.74 & $6.00^{* * *}$ & $6.09 * * *$ & 0.62 & 0.69 & 1.06 & 1.14 \\
\hline D PS HG & $4.59 * * *$ & $4.81 * * *$ & $6.75^{* * *}$ & $7.00 * * *$ & $2.25 * * *$ & $2.28 * * *$ & $3.84 * * *$ & $3.88^{* * *}$ \\
\hline D Male & $4.38^{* * *}$ & $4.53^{* * *}$ & $2.06^{* *}$ & $2.31 * *$ & -0.38 & -0.35 & $-2.57 * * *$ & $-2.32^{* * *}$ \\
\hline $\mathrm{R}^{2}$ & 0.225 & 0.223 & 0.232 & 0.224 & 0.111 & 0.108 & 0.187 & 0.178 \\
\hline adj. $R^{2}$ & 0.220 & 0.218 & 0.227 & 0.219 & 0.105 & 0.102 & 0.181 & 0.172 \\
\hline F-stat. & $45.58 * * *$ & $45.04 * * *$ & $44.56^{* * *}$ & $42.60 * * *$ & $19.49 * * *$ & $19.01 * * *$ & $33.95^{* * *}$ & $31.88^{* * *}$ \\
\hline Observations & 1105 & 1013 & 1042 & 977 & 1105 & 1013 & 1042 & 977 \\
\hline ECO110S & 60 & 41 & 53 & 24 & 60 & 41 & 53 & 24 \\
\hline ECO110H & 125 & 64 & 64 & 28 & 125 & 64 & 64 & 28 \\
\hline
\end{tabular}

Notes:

${ }^{1}$ Too few observations for grades A and B only. 
***, ** and * represent statistical significance at $1 \%, 5 \%$ and $10 \%$, respectively. White heteroskedasticity consistent standard errors and covariance test is used for all estimations.

Turning to the structured/essay question estimations for the first-year macroeconomics the ECO110S students achieve approximately 3.17 to 3.74 less than the ECO110F cohort. ${ }^{17}$ This difference is substantially lower than the 15 percentage point difference found for the first-year microeconomics course (see Table 5). As found earlier the advantage enjoyed by the academic development $(\mathrm{ECO} 110 \mathrm{H})$ over the ECO110S students appears to dissipate over time as the latter develop their writing skills. However, there are two other possibilities: the skills acquired in $\mathrm{ECO} 110 \mathrm{H}$ are not applied in ECO111S; or the structured/essay questions set in the ECO111S examination do not act as a particularly good discriminator between the three cohorts. The latter explanation appears to be most likely given the findings in respect of the multiple-choice questions and the relatively low weighting attached to writing in the ECO111S course and to structured/essay questions in the final examination. In the ECO203F examination the ECO110S cohort underperformed the ECO110F cohort by more than 11 percentage points in the structured/essay questions. The finding is statistically significant at the $1 \%$ level and holds for both the full and truncated samples. These findings may suggest that the English language and writing skills acquired in $\mathrm{ECO} 110 \mathrm{H}$ persist into the second-year microeconomics course or that some proportion of the ECO110H cohorts improved performance in the second-year microeconomics might be due to a better understanding of the principles of microeconomics.

These results also suggest that the performance of the ECO110H cohort is on a par with that of the ECO110F cohort controlling for academic ability. However, the $\mathrm{ECO} 110 \mathrm{H}$ cohort is subject to a number of educational and socio-economic disadvantages that are generally not experienced by mainstream students, some of which have been explored in parts 1 and 2. For example, area of residence, home environment, financial constraints and a general low level of academic preparedness, necessary to make a success of academic study at the tertiary level, which may not be measured by matriculation results. Therefore, it is suggested that these findings lend some support to the view that $\mathrm{ECO} 110 \mathrm{H}$ has been successful in enabling students to overcome some of their educational and socio-economic disadvantages relative to students from the ECO110F cohort.

The remaining findings are consistent with the earlier regression results. Matriculation points, physical science (HG) and mathematics (HG) improve performance, although the latter only for the multiple-choice questions in ECO203F (columns 3 and 4). Male students achieve, on average, at least 4.4 percentage points more than female students in the ECO111S multiple-choice examination (Columns 1 and 2). However, the premium is reduced by some 50\% in the ECO203F examination (Columns 3 and 4). This finding contrasts with that of Lumsden and Scott (1987) who found that the female disadvantage in multiple-choice questions increases over time. For ECO203F structured/essay questions the coefficients for Male are negative (Columns 7 and 8)

${ }^{17}$ The difference between the two coefficients for the ECO110H and ECO110S cohorts is only statistically significant at the $5 \%$ level for the full sample. 
providing support for international studies by Harris and Kerby (1997) and Greene (1997) who find that females enjoy a statistically significant advantage in structured/essay questions.

\section{CONCLUSION}

In this paper we investigate the effectiveness of a first-year academic development course in microeconomics on students' economics understanding in first-year microeconomics and subsequent courses in first-year macroeconomics and second-year microeconomics relative to a control group drawn from the mainstream. Three issues are addressed that have not been considered in previous studies: separate estimations are made for the multiple-choice and structured/essay questions that make up the final examination; an attempt is made to ensure deal with the sample-selection issues surrounding the composition of the control group; and the study estimates the effect of the first-year academic development course in microeconomics on students' performance in subsequent economics courses.

To the extent that the ECO110H cohort outperformed the control group, leaving aside the problem of sample-selection bias, it is possible to draw the following conclusions. The results suggest that ECO $110 \mathrm{H}$ has a major impact on students' performance in the structured/essay questions, relative to the control group, in first- and second-year microeconomics, and for the multiple-choice questions in first-year macroeconomics. The findings in respect of the multiple-choice questions for first-year and second-year microeconomics and the structured/essay questions for first-year macroeconomics are mixed.

The nature of the findings suggests that the aims of ECO110H - to improve students' learning, English language, writing and quantitative skills - are only partly met. The main impact of ECO110H, in the first-year microeconomics course, is on students' performance in the structured/essay questions. This suggests that $\mathrm{ECO} 110 \mathrm{H}$ has facilitated the improvement of students' English language and writing skills relative to the ECO110S cohort. The robust and positive nature of the relationship between $\mathrm{ECO} 110 \mathrm{H}$ and students' performance on the structured/essay questions, for the second-year microeconomics course, suggests that this skills advantage persists over time.

That said the better performance of the ECO110H cohort may be due to the greater effort that they exert, which may or may not have been stimulated by the course, or due to a selection of explanatory variables not included in the econometric estimations. Also, ECO110H is part of the Commerce Academic Development and "Gateway" programmes; it may well be that student performance is a result of the effects of $\mathrm{ECO} 110 \mathrm{H}$ and the other first-year courses in some combination. This does beg the question as to what the actual determinants of success in first- and second-year economics courses are, and also as to the role in determining this success played by each component of the academic development programme. 


\section{REFERENCES}

ANDERSON, G., BENJAMIN, D. and FUSS, M. (1994). The Determinants of Success in University Introductory Economics Courses. Journal of Economic Education, Spring: 99-119.

BANACH, J., FUZILE, L. \& RAMPEDI, W. (1992). Some pointers to causes of failure by African students in economics. SAAAD 92: Proceedings of the $7^{\text {th }}$ conference of the South African Association for Academic Development. 3-5 December.

BECKER, W.E. (1983a). Economic education research: Part 1, issues and questions. Journal of Economic Education, 14 (Winter): 10-17.

(1983b). Economic education research: Part 2, new directions on theoretical model building. Journal of Economic Education, 14 (Spring): 4-10.

(1983c). Economic education research: Part 3, statistical estimation methods, Journal of

Economic Education, 14 (Summer): 4-15.

, GREENE, W. and ROSEN, S. (1990). Research on high school economic education. Journal of Economic Education, 21 (Summer): 231-245.

—, HIGHSMITH, R., KENNEDY, P. and WALSTAD, W. (1991). An agenda for research on economic education in colleges and universities. Journal of Economic Education, 22 (Summer): 241 250 .

BRASFIELD, D.W., HARRISON, D. and McCOY, J. (1993). Impact of high school economics on the college principles of economics course. Journal of Economic Education, 24 (Spring): 99-112.

CASE, A. and DEATON, A. (1998). School quality and educational outcomes in South Africa. Research Programme in Development Studies, Princeton University.

CURTIS, P.J.D. and DE VILLIERS, J. (1992). The academic effectiveness of a bridging year for commerce undergraduates. Development Southern Africa, 9 (November): 457-470.

DAVENPORT, T.R.H. (1978). South Africa: A Modern History. MacMillan, South Africa.

DE VILLIERS, A.B. (1990). An evaluation of meta-learning in a first-year student development programme. South African Journal of Higher Education, 4 (2): 38-43.

DE VILLIERS, J. and RWIGEMA, H. (1998). The effect of a bridging year on the graduation success of educationally disadvantaged commerce students. South African Journal of Higher Education, 12 (1): 103-108. DE VILLIERS, M.F. (2004). Peer effects in educational outcomes with non-random assignment: results from the University of Cape Town. Unpublished Masters dissertation. School of Economics, University of Cape Town.

DOUGLAS, S. and SULOCK, J. (1995). Estimating production functions with correction for drops. Journal of Economic Education, 26 (Spring): 101-112.

EDWARDS, L. (2000). An econometric evaluation of academic development programmes in economics. The South African Journal of Economics, 68 (3): 455-483.

GREENE, B. (1997). Verbal abilities, gender, and the introductory economics course: A new look at an old assumption. Journal of Economic Education, 28 (Winter): 13-30.

HARRIS, R.B. and KERBY, W. (1997). Statewide Performance assessment as a complement to multiple choice testing in high school economics. Journal of Economic Education, 28 (Spring): 122-134.

HESKETH, J., MBALI, C. and MKHIZE, N. (1994). What makes them fail? An investigation into Economics 1A. Proceedings of the $9^{\text {th }}$ conference of the South African Association for Academic Development, University of Natal, Durban.

LOPUS, J. (1990). Do additional expenditures increase achievement in the high school economics class? Journal of Economic Education, 21 (Summer): 277-286.

LOPUS, J.S. (1997). Effects of the high school economics curriculum on learning in the college principles class. Journal of Economic Education, 28 (Spring): 143-153.

LUMSDEN, K. and SCOTT, A. (1987). The Economics Student Re-examined: Male-Female differences in Comprehension. Journal of Economic Education, 18 (Fall): 365-375.

MEYER, J.H.F. and SHANAHAN, M. (1999). Modelling learning outcomes in firstyear economics. 8th European Conference for Research on Learning and Instruction, Goteborg, Sweden, August 24-28.

MOLL, I and SLONIMSKY, L. (1989) Toward an understanding of cognition and learning in an academic support context. South African Journal of Higher Education, 3 (1): 160-166.

MOULDER, J. (1991). Remedial education programmes: Miracle or failure? South African Journal of Higher Education, 5 (1): 5-10.

MYATT, A. and WADDELL, C. (1990): An Approach to Testing the Effectiveness of the Teaching and Learning of Economics in High School. Journal of Economic Education, 21 (Summer): 355-363. 
PARK, K.H. and KERR, P. (1990). Determinants of academic performance: A multinomial approach. Journal of Economic Education, 21 (Spring): 101-111.

PAXTON, M. (1995). Tutor responses to student writing. South African Journal of Higher Education, 9 (1): 189-198.

- (1998). Transforming assessment practices into learning processes. Access to Success, ed. S.

Angelil-Carter, University of Cape Town Press, Cape Town.

PETERSON, N.A. (1992). The high school economics course and its impact on economic knowledge. Journal of Economic Education, 23 (Winter): 5-16.

RAIMONDO, H.J., ESPOSITO, L. and GERSHENBERG, I. (1990). Introductory class size and student performance in intermediate theory courses. Journal of Economic Education, 21 (Fall): 369-381.

RAMSDEN, P. (1992). Learning to Teach in Higher Education, Routledge, London.

REID, R. (1983). A note on the Environment as a Factor Affecting Student Performance in Principles of Economics. Journal of Economic Education, 14 (Fall): 18-22.

ROBB, R.E. and ROBB, A. (1999). Gender and the Study of Economics: The Role of Gender of the Instructor. Journal of Economic Education, 30 (Winter): 3-19.

SHANAHAN, M., FINDLAY, C., COWIE, J., ROUND, K., McIVER, R. and BARRETT, S. (1997).

Beyond the 'Input-Output' approach to assessing determinants of student performance in university economics: implications from student learning cantered research. Australian Economic Papers, September: 1737.

SIEGFRIED, J. and FELS, R. (1979). Research on Teaching College Economics: A Survey. Journal of Economic Literature, 17: 923-969.

and WALSTAD, W. (1990). Research on teaching college economics. The principles of economic course: A bandbook for instructors. eds. P. Saunders and W. Walstad, McGraw-Hill, New York. SLABBERT, J. (1994). Metalearning and education for all. South African Journal of Higher Education, 8 (1): 38-41.

SMITH L.C. (2004). A multivariate evaluation of mainstream and academic development courses in first year microeconomics at the University of Cape Town: A comparative study. Unpublished Masters dissertation, School of Economics, University of Cape Town.

TAY, R. (1994). Students' Performance in Economics: Does the Norm Hold Across Cultural and Institutional Settings? Journal of Economic Education, 25 (Fall): 291-301.

TERREBLANCHE, S. (2002). A History of Inequality in South Africa 1652-2002. University of Natal Press, Scottsville and KMM Review Publishing, Sandton.

VAN WALBEEK, C. (2004). Does lecture attendance matter? Some observations from a first-year economics course at the University of Cape Town. South African Journal of Economics, 72 (3): 11-32. VERWOERD, H.F. (1954). Bantu Education: Policy for the Immediate Future. Department of Native Affairs, Pretoria.

VOLBRECHT, T. (1999). Mainstreaming Academic Development at the University of the Western Cape: A case of "Mission Impossible" or just "Messiness Inevitable"? Academic Development, 4 (1).

WALKER, M. and BADSHA, N. (1993). Academic Development and the Challenge of Curriculum Change at the University of the Western Cape: An Overview. AD Dialogues, 1: 1-14.

WALSTAD, W. and SOPER, J. (1989). What is high school economics? Factors contributing to student achievement and attitudes. Journal of Economic Education, 20 (Winter): 23-38.

(1990). Research on high school economic education: a comment. Journal of Economic Education, 21 (Summer): 248-253.

- and Robson, D. (1997). Differential item functioning and male-female differences on multiple choice tests in economics. Journal of Economic Education, 28 (Spring): 155-171. 


\section{APPENDIX A}

\begin{tabular}{|c|c|c|c|c|}
\hline \multirow[b]{2}{*}{ Variable } & \multicolumn{2}{|c|}{$\begin{array}{l}\text { Multiple-choice questions } \\
\text { (MCQ) sample } \\
\text { Extended estimations }\end{array}$} & \multicolumn{2}{|c|}{$\begin{array}{l}\text { Structured/essay question } \\
\text { (SQ) sample } \\
\text { Extended estimations }\end{array}$} \\
\hline & Full & Truncated & Full & Truncated \\
\hline $\mathrm{C}$ & 7.30 & -21.28 & 49.20 & 47.16 \\
\hline $\mathrm{D} 110 \mathrm{H}$ & -1.47 & -14.59 & -8.10 & -33.09 \\
\hline Adjmatpt & 1.88 & $4.75^{* *}$ & -1.37 & -0.94 \\
\hline Adjmatpt $*$ Adjmatpt & -0.03 & $-0.10^{*}$ & 0.04 & 0.02 \\
\hline D110H* Adjmatpt & 0.11 & 0.88 & $1.17 *$ & $2.72^{* *}$ \\
\hline D Busecon & -2.82 & -3.47 & -1.68 & -4.98 \\
\hline D110H*D Busecon & -0.81 & 2.03 & -4.99 & 3.72 \\
\hline D Commerce & 1.30 & $3.62 *$ & 2.62 & $6.70^{* *}$ \\
\hline D110H*D Commerce ${ }^{1}$ & 1.20 & & 2.06 & \\
\hline D Economics & 0.19 & 0.82 & -3.25 & 1.25 \\
\hline D110H*D Economics & -1.88 & -5.82 & 0.64 & $-17.64^{* *}$ \\
\hline D Eng FL HG AB & 3.66 & 4.27 & 6.25 & 6.87 \\
\hline D Eng FL HG C & -0.39 & -0.76 & 0.16 & 0.23 \\
\hline D Eng FL HG D & 0.62 & & 0.32 & \\
\hline D EngFL HG E & 4.79 & & 9.69 & \\
\hline D Eng FL HG DE 2 & & 0.97 & & 0.37 \\
\hline D110H*Eng FL HG & 0.84 & -1.41 & 0.80 & 5.02 \\
\hline D Enghome & -1.88 & -3.42 & -1.58 & -5.01 \\
\hline D110H*D Enghome & -1.82 & -1.49 & $-8.92 *$ & $-16.79 * *$ \\
\hline D Male & $2.71^{* * *}$ & $3.65^{* *}$ & 0.66 & $4.78^{* *}$ \\
\hline D Math HG AB & $5.02 * *$ & & 3.55 & \\
\hline D Math HG ABC ${ }^{2}$ & & $7.51 * * *$ & & 4.36 \\
\hline D Math HG C & 3.07 & & 2.55 & \\
\hline D Math HG D & 1.42 & 0.13 & 4.42 & 1.13 \\
\hline D Math HG EF & $4.70^{* *}$ & $4.24 *$ & $8.40^{* *}$ & 6.77 \\
\hline D110H* Math HG & 0.10 & 5.35 & -2.83 & -0.39 \\
\hline D PS HG AB & 1.79 & & 4.51 & \\
\hline D PS HG ABC ${ }^{2}$ & & -0.02 & & 0.49 \\
\hline D PS HG C & -0.29 & & 0.01 & \\
\hline D PS HG D & 0.99 & 0.96 & 0.34 & 0.39 \\
\hline D110H*PS HG & -0.07 & 1.24 & 3.65 & $11.74 * *$ \\
\hline D Residence & $-3.37 * *$ & $-4.30 * *$ & -2.63 & -5.33 \\
\hline D110H*D Residence & 1.35 & -1.33 & 2.20 & -6.23 \\
\hline $\mathrm{R}^{2}$ & 0.171 & 0.268 & 0.243 & 0.264 \\
\hline adj. $R^{2}$ & 0.107 & 0.170 & 0.186 & 0.167 \\
\hline F-stat. & $2.70^{* * *}$ & $2.74 * * *$ & $4.23 * * *$ & $2.69 * * *$ \\
\hline Observations & 424 & 223 & 424 & 223 \\
\hline
\end{tabular}

\section{Notes:}

${ }^{1} \mathrm{ECO} 110 \mathrm{H}$ commerce students excluded from the truncated sample.

${ }^{2}$ Too few observations for grades A and B only.

$* * *, * *$ and $*$ represent statistical significance at $1 \%, 5 \%$ and $10 \%$, respectively. White heteroskedasticity consistent standard errors and covariance test is used for all estimations. 